\title{
Unregulated Private Health Sector: India's Challenges in Realizing Universal Health Coverage
}

\author{
Kesavan Sreekantan Nair Syed Arif Pasha \\ Department of Health Administration, College of Public Health and Health Informatics \\ Qassim University, Saudi Arabia
}

\begin{abstract}
Since India's independence in 1947, private health sector has witnessed a rapid growth. Today, private sector occupies a major share of health entities, health workforce and medical education institutions in the country. This paper provides an overview of private health sector in India, factors contributing to its growth, and major public policy implications in achieving universal health care based on extensive review of literature and other relevant descriptive information. The findings reveal that private health sector provides $80 \%$ of out-patient care and $60 \%$ of inpatient care in the country. There are 1.35 million private health entities delivering health services in the country, out of which 0.74 million are own account enterprises run by individual practitioners. About $76 \%$ of all private sector entities are allopathic facilities. This sector is largely unregulated with diversity of providers varying in qualifications, physical infrastructure, standards of care, technical knowledge, which are unfavorably affecting costs and quality of care. Strict implementation of regulations to influence private provider behavior in improving quality, reducing cost, appropriate use of medical technology, and accountability along with a huge investment in the public health sector are necessary to guarantee the availability, accessibility, acceptability, and quality of health services for every individual.
\end{abstract}

Keywords: private health sector, public health sector, health workforce, health insurance

DOI: $10.7176 / \mathrm{PPAR} / 10-3-07$

Publication date:March $31^{\text {st }} 2020$

\section{Background}

India's health system has been shaped by its federal structure with the responsibilities divided between central and state governments (GOI, 2017; Thomas, 2009). Health services in the country are delivered through a mix of public and private sectors. While the public sector delivers a comprehensive health care through its wide network of health facilities in rural and urban areas; the private health sector is very diverse which broadly comprises of formal and informal health care providers. In 1950, there were only 1352 private health entities of various categories throughout the country (Kumar, 2015). These entities have grown and diversified over a period of time which include hospitals, nursing homes, dental practice, nurses, physiotherapists, paramedical, diagnostic and pathological laboratories, blood banks, AYUSH (Ayurveda, Yoga, Unani, Siddha and Homeopathy) practitioners. Post-Independence period witnessed an abysmally low public expenditure on health care, which led to gross inefficiency and acute shortages services in public healthcare delivery system. In order to combat the growing health care needs of the population, the government invited private sector to act as complementary to the public sector, the areas where its services were deficient. Gradually, private healthcare facilities became the first point of contact to patients and gained importance among the population, due to their easy access to services in both rural and urban areas. Over the last few decades, private health sector in India has expanded rapidly, particularly after the economic reforms introduced by the government in 1990's. The pro-market strategies of the government encouraged private sector investment to bridge the gaps in health workforce, hospital beds and high-end technologies for delivering better quality health care to the population.

Presently, private hospitals deliver about $80 \%$ of out-patient care and $60 \%$ of inpatient care in the country (NSSO, 2016). Most of private health sector spending is in the form of out-of-pocket expenditures (OOP) by the households. According to the World Bank data in 2014, India's OOP was $62.4 \%$ of total health expenditure, which was one of the highest in the world (World Bank, 2014). Though the last decade witnessed a series of policy reforms with overall goal of strengthening public health system in rural and urban areas, but the recent national survey data shows that a significant share of population reported poor quality of available services as the key reason for not using public health facilities (NSSO, 2016). Overall contributions of private sector in terms of number of health entities, health workforce and medical education institutions are higher than that of the public health sector (GOI, 2017; Karan et al, 2019). Private health sector contributed to $70 \%$ of increase in all hospital beds in the country in between 2002 and 2010 (Gudwani et al, 2012).

Private sector proliferation has created many challenges in terms of quality of care, prices and unethical practices in health care market (Mackintosh, 2016). This sector is largely unregulated with diversity of health service providers vary in qualifications, physical infrastructure, standards of care, technical know-how, which are unfavorably affecting costs of care and technical quality. It is estimated that almost $40 \%$ of private health care is delivered by unqualified providers, who are not registered with the relevant professional councils (Thomas, 2009). 
During the last two decades, the government introduced a number of regulatory measures to address the accelerated growth of private sector including quality of care, cost of care, social accountability, and other ethical concerns which are posing serious problems on the poor population. Enforcing strict regulations in the private sector becomes difficult due to heterogeneity of entities, variations in infrastructure, staff, hospital charges, and gaps in implementation of regulations.

The objective of this paper is to provide an overview of private health sector in India and factors contributing to its growth, and major policy issues and challenges that come a long way in achieving universal health care in India.

\section{Methodology}

This paper is based on extensive review of literature conducted to stimulate relevant descriptive information on private health care sector in India. Latest information available through government documents, websites and studies related to private health sector in India were used. Data related to private health sector is seldom available in the public domain. Major sources of information on number and size of private health institutions, share of private sector in health service utilization and private health spending are available through the surveys of National Sample Survey Organization (NSSO). The estimates based on NSSO data by recent studies have been used extensively. The major focus was given on growth of private health sector, factors contributing to its growth, and major challenges come a long way in achieving universal health care. The publications of WHO, World Bank, reports of Ministry of Health and Family Welfare, academic articles related to the area of focus were used. The pertinent literature, thus collected from numerous sources was used as a way of triangulation to provide integrity to the analysis. Using electronic database, an in-depth literature search was also conducted to identify recent peerreviewed studies on health system in India.

\section{Size and growth of private health sector}

When India became independent from the British rule in 1947, the private health sector contributed about $8 \%$ of patient care (Sengupta \& Nundi, 2005). Private health providers in Indian economy recorded a rapid growth after 1990-91 liberation policy of the government (Kumar, 2015). During this period the government's role was limited to a facilitator for establishment of health facilities rather than a strong regulator. Low public spending on health during this period, further gave leverage to the private sector proliferation in health care market. The government encouraged private sector investment in health sector through a number of avenues such as providing long term loan at low interest rates, benefits like reduced custom duty for import of high tech medical equipment, drugs and income tax exemption (Sengupta \& Nundi, 2005; Shah \& Mohanty,2011). In order to encourage entry of big players in health care industry, large hospitals were given generous land concessions at prime locations in the country with the condition that these hospitals should reserve a minimum of $10 \%$ of beds for treatment of the poor patients free of cost (Dehury et al, 2019). The government policy of allowing 100\% foreign direct investment (FDI) in hospital industry was one of the major initiatives attracted investment in hospital industry; and as a result, number and volume of foreign investment in hospital sector have increased manifold times (Dehury et al, 2019; Kurian, 2016).

NSSO data for 2010-11 provided an estimate of 1.35 million private health entities delivering health services in the country, out of which 0.74 million were own account enterprises, mainly run by individual practitioners, who mostly deliver outpatient services (NSSO, 2013). Allopathic medicines constitute a major form of practice by the private health providers and estimate for $2010-11$ shows about $76 \%$ of all private sector entities were allopathic facilities (NSSO, 2013). Private sector employs a huge share of health workforce in the country, which includes the self-employed. The estimate based on NSSO data for 2016 shows almost $53 \%$ of health workforce in the private sector is self-employed (Karan et al, 2019). More than $80 \%$ of physicians, $90 \%$ dental practitioners, $55 \%$ of nurses and midwives were employed in the private sector (Fig.1). This sector has also taken a predominant share of health service delivery in the country for the last several decades and according to NSSO, private health sector provides more than two-thirds of inpatient care and about one-fifths of outpatient care in the country in 2016. Their share in the medical education has increased at a rapid rate. At the time of independence, all medical education institutions were funded and organized by the government (Diwan et al, 2013; Patel et al, 2015). Since then, the government made efforts to encourage private sector investment in medical education sector, but the contribution of this sector was abysmal till early 1990's (Rao et al, 2009).

Government's pro-market policies, limited government funding to medical education and increasing willingness to pay for medical education by the people further led to impressive growth of private medical colleges in the country (Qadeer, 2006; Mahal \& Mohanan, 2016). According to the latest report of Ministry of Health (2019), the share of private medical colleges has increased from 3.6\% in 1965 to $55.4 \%$ in 2017 (Fig:2). 


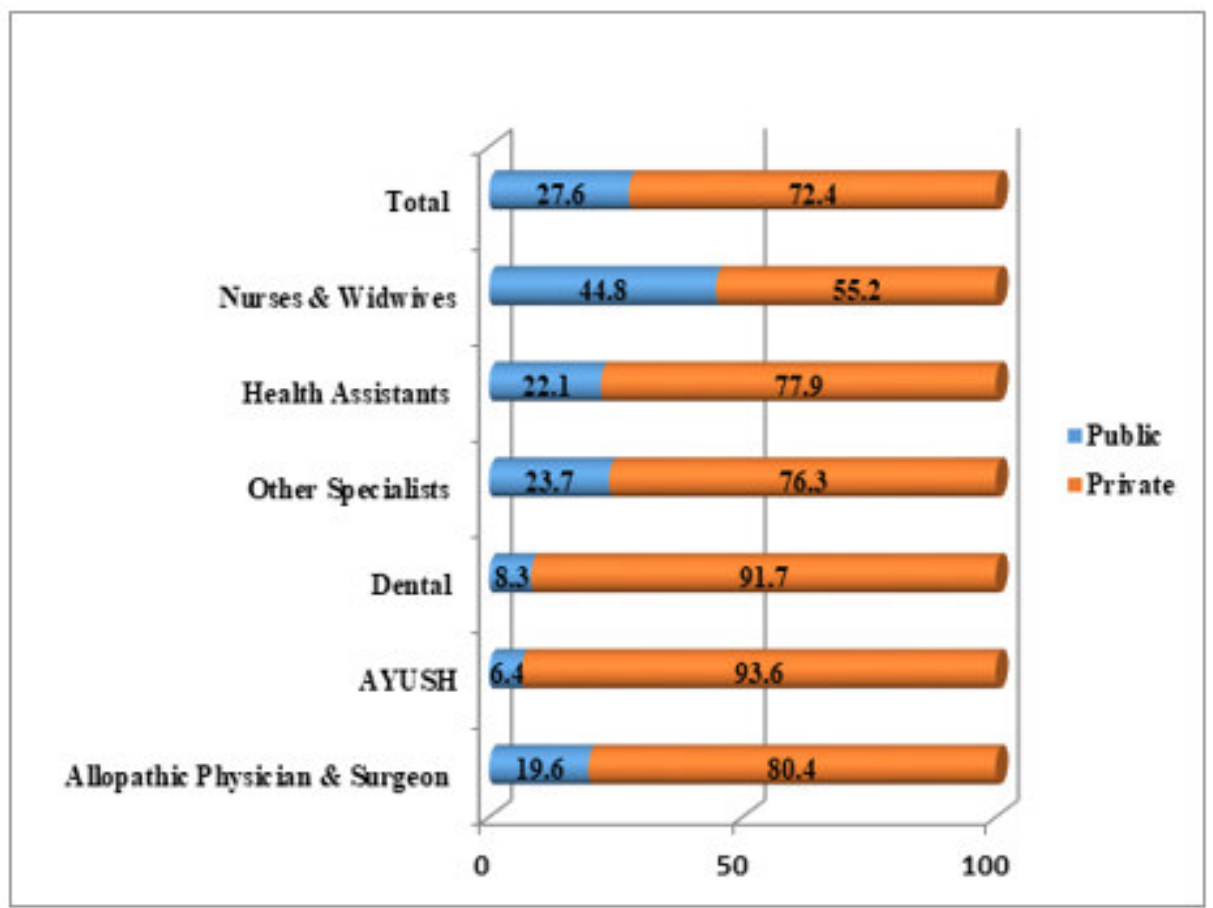

Figure 1: Distribution of health workforce between public and private sector in India, 2016

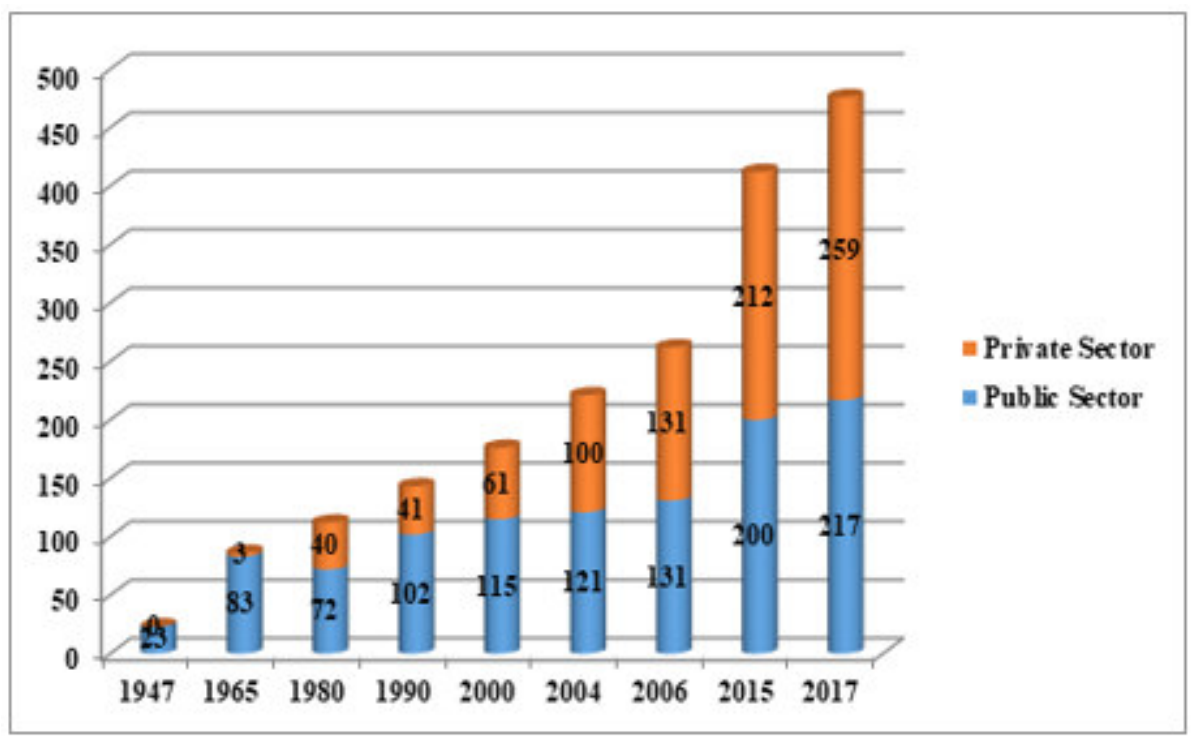

Figure 2: Number of medical colleges in public and private sector in India 1947-2017

\subsection{Health Financing}

India's public health expenditure is one of the lowest when comparing to other developing nations (GOI, 2017). The public health expenditure as a share of GDP was only $1.15 \%$ in 2013-14, which translates into US $\$ 62$ per capita at current prices; this figure is much lower than India's neighboring countries like Thailand (US\$214) and Srilanka (US\$93) (WHO, 2014). In 2015-16, both central and state governments together contributed to $24 \%$ of total health expenditure, which is far below the global average of $60.1 \%$ and slightly below the average of lowermiddle income countries of $36.2 \%$ (GOI, 2018). Despite the implementation of world's largest flagship program of National Rural Health Mission (NRHM) and its commitment to increase public health spending, the overall public health spending remains much below the global average. Data shows that total expenditure on health as \% of GDP declined from $4.5 \%$ in 2004-05 to $4 \%$ in 2013-14, despite increase in real per capita health expenditure (GOI, 2018).

The growth of private health sector in India is also influenced with the changing landscape of health financing; from the traditional tax-based health funding to providing financial protection through health insurance. The 
liberalization of the insurance sector and establishment of an oversight body called Insurance Regulatory and Development Authority (IRDI) in 1999 gave impetus to private sector participation in insurance. Gradually, the insurance sector was opened up for foreign players in health insurance and FDI cap in health insurance sector increased from $26 \%$ to $49 \%$ in 2014 . With these developments, private health insurance business has recorded $25 \%$ growth during the past few years (Gambhir et al, 2019). Health insurance has stimulated the growth of health care demand and thus health services delivery. As major share of health spending is OOP by individuals, health insurance market has a huge potential for growth and is expected to grow at a faster rate in the future. According to Oxford Economics (2018) forecast, the private health insurance spending in India is expected to record a sharp raise from US\$2.5 billion in 2010 to US\$ 3.5 billion in 2021 . With the commitment towards providing financial protection to the poor segment of population against catastrophic health shocks, both the union and state governments have initiated health insurance schemes; which have provided an impetus to the health insurance industry. In 2008, the union government introduced Rashtriya Swasthya Bima Yojana (RSBY) aiming at providing health insurance coverage to the poor families and 11 other categories of unorganized workers under which each family enrolled in the scheme was entitled to hospitalization benefits up to Indian Rupees 30,000 per year in government as well as empanelled private hospitals. A network of more than 7000 hospitals was developed by empaneling huge number of private hospitals under the scheme. By 2018-19, the scheme covered about 206.5 million poor, which accounted for $65.45 \%$ of the target population (Malhotra et al, 2018). However, this scheme is subsumed with recently launched Ayushman Bharat - a national health protection scheme, which is one of the largest government sponsored scheme providing health coverage of Indian Rupees 0.5 million for a family per year, for secondary and tertiary care hospitalization. The scheme is targeted to cover about 50 million poor individuals who are entitled for cashless and paperless treatment at the designated hospitals. Notable health insurance among state governments is Yeshaswini scheme in Karnataka and Rajiv Aarogyasri in Andhra Pradesh state (Patel et al, 2015; Reddy \& Mary, 2013). These government sponsored schemes mostly rely on private health providers.

\subsection{Changing Demographic and Health Scenario}

India's urban population, which constitutes $31.2 \%$ of the population, is continuously growing and live in larger cities and towns. During the decade 2001 to 2011, population in urban areas has increased by $31.8 \%$ which was 2.6 times the corresponding decadal increase for rural population of $12.18 \%$. India's life expectancy at birth has improved from 60.2 years in 2001 to 66.2 years in 2011, as a result of advancement in medical care and control of communicable diseases (RGI, 2011). With the improvement in life expectancy, the number of elderly population has increased to $9 \%$ of total population in 2011 and is expected to grow by $11 \%$ by 2025 and $19 \%$ by 2050 , which will have larger implications on additional medical care facilities for treatment of chronic diseases (IIPS, 2013; Liu et al, 2015). In 2013, India accounts for almost $20 \%$ of the global burden of disease, $21 \%$ of all child deaths and $27 \%$ of all neonatal deaths in the world (GBD). Non-communicable diseases in the country account for $52 \%$ of all disease burden and about $60 \%$ of all deaths (IHME, 2013). There has been tremendous increase in life style and emerging diseases including those due to environmental hazards, which requires establishment of new hospitals infrastructures including health workforce.

\subsection{Medical Tourism}

Globalization has boosted the growth of medical tourism and has elevated nations out of their secluded existence. Promotion of medical tourism as a public policy has been one of the major factors that led to growth of corporate hospitals across India. The country has emerged as one of the major medical tourism destination in the world constituting about $18 \%$ of the world medical tourism market (GOI, 2019). The size of medical tourism market in India was estimated at US\$3 billion (Indian Rupees 195 billion) and is expected to reach US\$ 9 billion by the end of 2020. Medical tourism is expected to grow at a higher rate due to government's favorable policy initiatives to promote health and medical tourism along with the public private partnership initiatives and incredible India campaign' in home and abroad by the ministry of tourism. The government has simplified visas for multiple entries and long stay for the patients and attendants including e-medical visa for 166 countries. Many factors like quality medical care, use of high-end technology, affordable cost, ease of communication, low cost of living, rich cultural heritage and less waiting time for treatment have increasingly encouraged foreigners to avail medical treatment in India. The costs of medical treatment in India are comparatively lower ranging from one-eighth to one-fifth of costs in the western countries and is more cost competitive even comparing to other leading medical tourism countries in Asia (Hazarika, 2010).

\section{Regulation of the Private Health Sector}

Health, being a state subject in India, it is the prerogative of state governments to regulate the private sector. Over the years, several legal and administrative regulations have been enacted at the central and state levels with the objective of protecting patients and enhancing quality of care (Chakravarthi, 2018). Clinical Establishment 
(Registration and Regulation) Act (CEA) was passed in the Indian Parliament in May 2010, which applied to all types of healthcare providers and clinical establishments managed by private, government, trust or societies. The act covers corporates and private practitioners, dental care, and services of AYUSH practitioners, all types of laboratories, diagnostic and therapy centers. The act, however, did not have provision for regulating the price and quality of health care delivered in health facilities. Other legislations include pre-conception and prenatal diagnostic technologies act, enacted in 1994 to stop female foeticide and medical termination of pregnancy act of 1971, which lays down the conditions under which pregnancies can be terminated. The professional councils for physicians, nurses and pharmacists regulate their respective professions for different system of medicine such as allopathic, ayurvedic, homeopathic and unani. These councils are legally empowered bodies which regulate medical education, recognize qualifications for registration and ensure that all members follow the code of conduct laid down by the respective councils (Phadke, 2016). CEA act, which was amended later, specifies minimum standards for all public and private clinical establishments in the country, including prices to be charged for procedures and services as determined by the central government in consultation with the states. The act also stipulates fines and penalties if provisions of the law are breached by any facility. Strict implementation of this act would go a long way toward improving quality assurance as envisaged by health policies.

The government also regulates professional and technical education, food safety, medical technologies, medical products, clinical trials, research and implementation of other health related laws through the Ministry of Health and Family Welfare (MOHFW). The recent national health policy, while emphasizing major reforms in medical education system also recommends setting up of a council for allied health professionals, effective adoption of standard treatment guidelines and protection of patient rights in clinical establishments. The policy also recommends setting up of an empowered medical tribunal for disputes regarding standards of care, prices, negligence and unfair practices; setting up of standard regulatory framework for specialized services like organ and tissue transplantation, stem cell banking, and nano medicine. The national accreditation board for hospitals and healthcare providers (NABH) under the quality council of India (QCI) provides benchmarks and accreditation of hospitals. Though number of hospitals accredited and certified is increasing, but these are mostly done on voluntary basis and not legally mandated. The regulations have been ineffective owing to number of factors such as resistances from stakeholders, weak monitoring and enforcement mechanism, inadequate manpower and budget, administrative bottlenecks, corruption and weak bureaucratic and judiciary systems, and limited political will towards regulation (Sheikh et al, 2015).

\section{Discussion and Policy Implications}

Private health sector has emerged as vibrant force contributing to economic growth in India. Apart from the promarket reform policies of the government and creation of competitive investment opportunities, many other factors like increased demand for healthcare services, rising incomes, improved access to health insurance, and increased healthcare awareness among population have attributed to this growth phenomenon. Further, the increased public expenditure on social health insurance, and more particularly the roll out of the Ayushman Bharat programme provides a stimulus to health care market and addresses the enduring demand side gaps afflicting the health care industry. Overall, the private sector in healthcare industry has established itself in a well-poised position to tap growth opportunities and future development of health care market in India.

Private health sector plays a complementary role in the provision of health services in India, by assisting the government to increase the density of hospital beds to the patients which is currently quite low (1.30 per 1000 population) in comparison to world average of 2.60 and the WHO recommended norms of 3.50. However, this mere expansion of bed capacity does not cater to the health needs of majority of the poor living in rural areas. Private hospitals are mostly concentrated in metropolitan cities, and larger towns with the reason being that in order to generate profits the entities should basically dependent on population who are willing and able to pay for services. Corporate hospitals established in metropolitan cities are less crowded, well organized, patient friendly, and depending on patients belonging to affluent category can avail of luxury facilities including spas (Ghoshal, 2015). They cater to health care needs of patients having health insurance, tie-up with corporate sector, and referrals from smaller hospitals. Despite the provision for reserving $10 \%$ beds for treatment of poor patients, access to the services to them is limited. There are reports of refusal of treatment due to outstanding hospital bills, withdrawn of life support system for those patients unable to pay and refusal of emergency cases at first hand. Generally, private health providers have been criticized on the ground that they overprescribe medicines and advise for unnecessary diagnostic tests with the motive to generate revenue (Sengupta \& Nundi,2005; Decosta \& Diwan, 2007; Phadke, 2016). There are instances where caesarean sections performed in private maternity hospitals are high although WHO has suggested the upper limit of lower than 15\% for caesarean section (Chaillet et al, 2007). The national household surveys shed lights on the link between catastrophic health expenditures and utilization of health care from the private sector (Berman et al, 2010). In comparison to public health sector, cost of hospitalization in the private health sector was about 3.9 times higher in rural areas and 4.02 times higher in urban areas in 2014 (NSSO, 2016). Studies have shown that medical expenditures are one of the triggers of 
impoverishment in the country and health insurance is considered as a key mechanism to reduce financial risk protection, however experiences show there exist many challenges like supply side moral hazard, unethical practice, fraudulent claims, and cherry picking of profitable interventions. With these reasons, the private sector accounts for almost $80 \%$ of reimbursement claims under health insurance (PHFI, 2011). There are reports that insured cases under the social health insurance are treated late due to delay in approval by insurance companies. The health rights movement and philanthropic organizations are seriously demanding state regulation of private sector to put a check on escalating costs of health care (Shetty, 2010; Shukla et al, 2018).

Though medical tourism has made tremendous growth of corporate sector, it has created a huge divide between public and private sector in health system. While the economically better off receives quality services in urban areas, the population living in rural areas still faces the problem of inadequate access to quality services, specialty care and even essential medicines. Furthermore, the growth of medical tourism attract experienced health professionals to the private sector, owing to their attractive package, greater career growth and work environment which further adds to shortage of health professionals in the public sector in rural areas. Since there has been huge disparity in availability of health services between rural and urban areas, it is the responsibility of the government to prioritize provision of quality and affordable health care in vast majority of population in rural areas.

The poor population prefers to utilize health services from private providers mainly due to inadequate availability of services from public health facilities, and the problem is so severe in the rural and remote areas in the country. The quality of services delivered by the private providers differs as compared to that in the urban areas (Bowser et al, 2019; Chatterjee et al, 2019). Thus the poor are the victims of unregulated spread of private health services, as they require better care at affordable cost. There are increasing gaps in health care utilization by different income groups from both public and private sectors in the country; and the high income groups benefit from the better quality health care from the private hospitals as well as subsidized health care from the government hospitals (Acharya, 2018; Baru et al, 2010). Within private sector, the spectrum of quality of care is widely varied (Baru, 2013). On the one side, there are large super specialty hospitals with medical technology, infrastructure, health professionals and clinical outcomes comparable to world class hospitals; on the other side, there are small nursing homes registered as hospitals with poor quality standards offering services to different segment of population at differential prices. Private providers are the first point of contact for most common ailments in rural and urban areas, but significant share of them are unqualified and underqualified. A study conducted in a central Indian state revealed that only $11 \%$ of private providers covered in the study had a medical degree and only $53 \%$ of them completed high school education (Das et al, 2012). These entities often do not adhere to patient safety standards. Without the comprehensive quality monitoring system either at the state or at central level, clinical experience and patient experience remains a tenuous area. Inadequate government funding on health care not only leads to deficient services, infrastructure and trained health workforce, but also lead to poor access to quality health care services to a majority of population in India. The recent policy and program announcements in health sector give a clear indication of the government's commitment to address the issues of improving quality, accessibility and affordability of health care services. However the nitty-gritty of implementation should take in to consideration the accountability of all stakeholders in the system from all types and sizes of health service providers.

It is beyond doubt private health sector has made remarkable progresses but this growth has transpired at the cost of public health sector. Still there is huge unmet demand for healthcare in the country, which offers enormous potential for the growth of private health sector. Further with the changing socio, economic and demographic scenarios, there will be huge demand for quality health care in future, creating opportunities for new entry in health care market. India is currently passing through the epidemiological transition with increasing burden of noncommunicable diseases. In this context, primary health care facilities play a greater role in tackling the noncommunicable diseases like diabetes and hypertension; but due to lack of staff, diagnostic facilities, and medicines, huge number of patients prefer to seek care at private health facilities (Gabert et al, 2017; Elias et al, 2018; Pakhare et al, 2015). Even older population with diabetes or hypertension are more likely to seek care at private health facilities; technical quality has been the most cited reasons for non-utilization of public health facilities for these chronic ailments (Kujawaski et al, 2018).

The private sector has a huge potential for delivering preventive and promotive health services in the country and their role is reflected in various policy documents which have clearly emphasized that government should influence the operation and growth of the private health facilities and medical technologies in alignment with public health goals through appropriate regulations. In this context, NRHM which is one of the largest flagship program in health sector in the world, set up in 2005, sought to provide universal access to equitable, affordable and quality health care through an architectural correction of government health system (MOHFW, 2005). The National Urban Health Mission (NUHM), launched in 2014, to meet the health care requirements of poor in urban areas also emphasized the potential role of private health sector in delivering public health services (MOHFW, 2012). In order to fill critical service gaps in public health facilities, the NHP encourages contracting and strategic purchasing from the profit and non-profit organizations in alignment with the public health goal (GOI, 2017). It further emphasized exploring collaboration for primary care services with not- for -profit organizations in rural 
and remote areas by developing their skills to meet public health goals.

The present problem of scarcity of doctors in the rural primary healthcare system is due to age old problems of poor remuneration package, frequent transfers, and lack of promotion avenues besides unsafe and unsatisfactory working environment (Bajpai, 2014). This led to emergence of unqualified health practitioners who serve as the first point of contact to significant number of population. The urban pockets also face the brunt of such untrained practitioners. Realizing this fact, the government has considered series of initiatives for mobilizing private health practitioners toward delivery of public health serves (Sembiah et al, 2018). Adherence to standard treatment protocol of common health problems by health providers and uniformity in treatment can prevent delay in diagnosis of the problem, delay in referrals and unnecessary financial burden by the poor. Globally there are evidences from countries where irrational use of antibiotics and non-adherence to standard treatment procedures are common by private medical practitioners (WHO, 2005; Sembiah et al, 2018). Countries like India needs to consider capacity building of private practitioners on the use of standard treatment protocol on continued basis and ensure that they practice these protocol is one of the solution.

Accomplishing the goal of providing equitable access to quality of care at affordable charges to population requires resolving all fundamental structural issues confronting the health sector. Apart from making efforts to reducing out-of-pocket health expenditures, the government should set up a quality monitoring mechanism to monitor clinical outcomes, hospital infection rates, and patient safety culture of all public and private hospitals across the country. The hospitals that are consistently delivering best standards of care in diverse dimensions of patient care, and best clinical practices may be rewarded or incentivized and defaulters could be penalized so as to encourage compliance on standard quality of care. Along with quality monitoring it is also important to rationalize pricing of health services by undertaking studies on standard treatment protocols and based on best clinical practices which will greatly contribute to reduction in out-of-pocket expenditures by individuals. Additionally, the government funding for primary care should be increased to create robust primary health care networks along with creating adequate pool of skilled health professionals in rural and urban areas.

\section{Conclusion}

India witnessed a dramatic growth of private health sector during the last few decades mainly due to longstanding weakness in public health system and pro-market strategies adopted by the government since 1990's. Private health sector fills the vacuum where the public health sector is unable to provide due to low public health spending, deficient health infrastructure, lack of trained health workforce, medical equipment and supplies, leading to uneven and often poor quality of care offered at government health facilities. However, there are many challenges with regard to engagement of this sector in terms of quality, prices and unethical practices. Private health sector, which delivers health care to largest segment of Indian population in both rural and urban areas is largely unregulated with diversity of providers vary in qualifications, physical infrastructure, standards of care, technical knowledge, which are unfavorably affecting costs of care and technical quality. Further this sector is susceptible to overuse and misuse of medical technology, corruption, unethical practices, and lack of accountability including medical negligence. Despite legal and regulatory mechanisms are in place, the presence of commercial interest, dominance of professional associations, plurality of actors, political pressure groups, growing influence of corporate players in policy making have adversely impacted the smooth implementation process. Innovative approaches are required to influence provider behavior, which is considered as a critical element in improving quality, reducing cost, appropriate use of medical technology, and accountability. Along with the comprehensive regulations, a strong involvement of professional associations, consumer rights movement and public support are required. While highlighting the role of private sector in health care provision in achieving universal health coverage in India, all public policies and programs have also emphasized the overarching goal of strengthening the public health system to improve equity in the availability, utilization and affordability of health services to Indian population.

\section{References}

Acharya, S.S. (2018). Health equity in India: an examination through lens of social exclusion. Journal of Social Inclusion Studies, 4(1), 104-130.

Bajpai, V. (2014). The challenges confronting public hospitals in India, their origins, and possible solutions. Advances in Public Health, Retrieved from https://www.hindawi.com/journals /aph/2014/898502/. Accessed August 6, 2019.

Baru, R., Acharya, A., \& Acharya, S. (2010). Inequities in access to health services in India: caste, class and religion. Economic and Political Weekly, 45(38), 49-58.

Baru, R.V. (2013). Challenges for regulating the private health services for achieving universal health care. Indian Journal of Public Health, 57(4), 208-11.

Berman. P., Ahuja, R., \& Bhandari, L. (2010). The impoverishing effect of healthcare payments in India: new methodology and financings. Economic and Political Weekly, 45(16), 65-71.

Bowser, D., Patenaude, B., Bhawalkar, M., Duran D., \& Berman, P. (2019). Benefit incidence analysis in public 
health facilities in India: utilization and benefits at the national and state levels. International Journal for Equity, 18(13).Retrieved from https://equityhealthj. biomedcentral.com/ track/pdf/10.1186/s12939-0190921-6.

Chaillet, N., Dube, E., Francoeur, D., Dube, J., Gagnon, S.,..... Dumont, A. (2007). Identifying barriers and facilitators towards implementing guidelines to reduce caesarean section rates in Quebec. Bulletin of World Health Organization, 85(10), 791-7.

Chakravarty, I.(2018). Regulation of private health care providers in India: current status, future directions. Indian Journal of Public Administration, 64(4), 587-598.

Chatterjee, C., Nayak, N.C., Mahakud, J., \& Chatterjee, S.C.(2019). Factors affecting the choice of health care utilization between private and public services among the elderly population in India. 34(1):e736-e751. Retrieved from https://onlinelibrary.wiley.com /doi/full/10.1002/ hpm.2686.

Das, J., Holla, A., Das, V., Mahajan, M., Tabak, D., \& Chan, B. (2012). In urban and rural India, a standardized patient study showed low levels of provider training and huge quality gaps. Health Affairs, 31: 2774-84.

De Costa, A., \& Diwan, V. (2007). Where is the public health sector?' Public and private sector healthcare provision in Madhya Pradesh, India, Health Policy, 84 (2-3):269-76.

Dehury, R.K., Samal, J., Coutinho, S., \& Dehury, P. (2019). How does the largely unregulated private health sector impact the Indian mass?. Journal of Health Management. 21(3), 383-393.

Diwan, V., Minj, C., Chhari, N., \& De Costa, A. (2013). Indian medical students in public and private sector medical schools: are motivations and career aspirations different? - Studies from Madhya Pradesh, India. BMC Medical Education. 2013; $\quad$ 13(127). Retrieved from https://bmcmededuc.biomedcentral.com/articles/10.1186/1472-6920-13-127.

Elias, M.A., Pati, M.K., Aivalli, P., Srinath, B., Munegowda, C., \& Srinivas, P.N. (2018). Preparedness for delivering non-communicable disease services in primary care: access to medicines for diabetes and hypertension in a district in south India. BMJ Glob Health, Retrieved from 2:e000519. https://gh.bmj.com/content/2/Suppl_3/e000519.

Gabert, R., Ng M, Sogarwal, R., Deepu, R.V., McNellan, CR., Mehra, S., .....Duber, H.C. (2017). Identifying gaps in the continuum of care for hypertension and diabetes in two Indian communities. BMC Health Serv Res, 17: 846. doi: 10.1186/s12913-017-2796-9.

Gambhir, R.S., Malhi, R., Khosla, S., Singh, R., Bhardwaj, A., \& Kumar, M. (2019). Out-patient coverage: private sector insurance in India. J Family Med Prim Care. 8(3), 788-792.

Ghosh, S. (2014). Trends and differentials in health care utilization pattern in India. Journal of Health Management 16(3), 337-363.

Ghoshal, R. (2015). What ails India's two-tiered healthcare system? A philosophical enquiry. Indian Journal of Medical Ethics. 12 (1):25-29.

Government of India. (2018). National health accounts estimates for India Financial Year 2015-16.National Health Systems Resource Centre, Ministry of Health \& Family Welfare, New Delhi. 2018.

Government of India. (2019). Economic survey 2018-19.https://www.indiabudget.gov.in/ economicsurvey/. Accessed 28 August 2019.

Government of India. Ayushman Bharat Pradhanmantri Jan Arogya Yojana. National Health Authority. https://www.pmjay.gov.in/. Accessed August18, 2019.

Government of India. National Health Policy- 2017. Ministry of Health and Family Welfare. Government of India. 2017.

Gudwani A., Mitra P., Puri A., \& Vaidya M. India healthcare: inspiring possibilities, challenging journey. New York: McKinsey \& Co, 2012.

Hazarika I. (2010). Medical tourism: its potential impact on the health workforce and health system in India. Health Policy and Planning, 25: 248-251.

Institute for Health Metrics and Evaluation (IHME). (2015). Global Burden of Disease Study. (2013). Global Burden of Disease Study 2013 (GBD 2013) Incidence, Prevalence, and Years Lived with Disability 19902013. Seattle, WA.

International Institute for Population Sciences. Study on global ageing and adult health-India national report. Mumbai. 2013.

Karan A., Negandhi., Nair R et al. (2019). Size, composition and distribution of human resources for health in India: new estimates using national sample survey and registry data. BMJ Open.2019;9:e025979.doi:10.1136/bmjopen-2018-025979.

Kujawski SA., Leslie HH., Prabhakaran D, et al. (2018). Reasons for low utilization of public facilities among households with hypertension: analysis of a population based survey in India. BMJ Glob Health, 3:e01002. Retrieved from https://gh.bmj.com/content/3/6/e001002. Accessed August 3, 2019.

Kumar, C., \& Prakash, R. (2011). Public-private dichotomy in utilization of health care services in India. Consilience: The Journal of Sustainable Development, 5(1), 25-52. 
Kumar, S. (2015). Private sector in healthcare delivery market in India: structure, growth and implications: working paper 185. Institute for Studies in Industrial Development. New Delhi.

Kundu, M.K, Hazra, S., Pal, D., \& Bhattacharya, M. (2018). A review on Non-communicable Diseases (NCDs) burden, its socio-economic impact and the strategies for prevention and control of NCDs in India. Indian Journal of Public Health, 62(4), 302-304.

Kurian, O.C. Financing healthcare for all in India: towards a common goal. Retrieved from https://www.oxfamindia.org/sites/default/files/WP-Financing-Healthcare-for-All-In-India-29-05-2015EN_0.pdf.

Liu, L., Oza, S., Hogan, D., Perin, J., Rudan, I.,........Black, R.E.(2015). Global, regional, and national causes of child mortality in 2000-13, with projections to inform post-2015 priorities: an updated systematic analysis. Lancet, 385: 430-40.

Mackintosh, M., Channon, A., Karan, A., Selvaraju, S., Cavagnaro, E., \& Zhao H. (2016). What is the private sector? Understanding private provision in the health systems of low income and middle income countries. The Lancet, 388 (10044):596-605.

Mahal, A., Mohanan, M (2006). Growth of private medical education in India. Med Ed, 40(10):1009-1011.

Malhotra, S., Patnaik, I., Roy, S., Shah, A. (2018).Fair play in Indian Health Insurance, Working paper series no.228 National Institute of Public Finance and Policy. Retrieved from https://nipfp.org.in/media/medialibrary/2018/05/WP_228.pdf.

May, C., Roth, K., \& Panda, P. (2014). Non-degree allopathic practitioners as first contact points for acute illness episodes: insights from a qualitative study in rural northern India. BMC Health Serv Res, 14, 1-11.

Ministry of Health and Family Welfare. National Health Profile 2018. Central Bureau of Health Intelligence. Government of India, 2019.

Ministry of Health and Family Welfare. National Rural Health Mission- Framework for implementation. Government of India. New Delhi.2005.

Ministry of Health and Family Welfare. National Urban Health Mission- Framework for implementation. Government of India. New Delhi.2012.

Nandi, S., Schneider, H., \& Garg, S. (2018). Assessing geographical inequity in availability of hospital services under the state-funded universal health insurance scheme in Chhattisgarh state, India, using a composite vulnerability index. Glob Health Action, 11 (1). Retrieved from https://www.ncbi.nlm.nih.gov/pmc/articles/PMC6237177/. Accessed August 21, 2019.

National Sample Survey Organization. Health in India- NSS $71^{\text {st }}$ round. Ministry of Statistics and Program Implementation. Government of India.2016.

National Sample Survey Organization. Survey on unemployed non-agricultural enterprises. NSS 67th round. Ministry of Statistics and Program Implementation. Government of India.2013.

Office of the Registrar General. Provisional population totals, New Delhi: Office of the Census Commissioner. Office of Registrar General, India, 2011.

Oxford Economics. (2018). Global analysis of health insurance in India. Retrieved from https://www.ey.com/Publication/vwLUAssets/EY-global-analysis-of-health-insurance-in-india/ \$File/eyglobal-analysis-of-health-insurance-in-india.pdf.

Pakhare, A., Kumar, S., Goyal, S., \& Joshi, R. (2015). Assessment of primary care facilities for cardiovascular disease preparedness in Madhya Pradesh, India. BMC Health Serv Res;15:408. Retrieved from https://www.ncbi.nlm.nih.gov/pmc/articles/PMC4580030/.

Patel, V., Parikh, R., Nandraj, S., Narayan, K., Paul VK., ...........Reddy, K.S.(2015). Assuring health coverage for all in India. Lancet, 5, 386:2422-35.

Phadke, A. (2016). Regulation of doctors and private hospitals in India. Economic and Political Weekly. 51(6), 46-55.

Public Health Foundation of India. (2011). A critical assessment of the existing health insurance models in India: A research study. New Delhi: Public Health Foundation of India to the Planning Commission. Government of India.

Qadeer, I. (2006). The real crisis in medical education. Indian J Med Ethics, 3:95-9.

Raman, AV., \& Bjorkman, J.W.(2008). Public-private partnerships in health care in India: lessons for developing countries. London: Routledge.

Rao, K. D., Bhatnagar, A., \& Berman, P.(2009).India's health workforce: size, composition, and distribution. India Health Beat, 1(3), 14.

Reddy, S., \& Mary, I. (2013). Aarogyasri Scheme in Andhra Pradesh, India: Some Critical Reflections, Soc Change, 43, 245-61.

Sembiah, S., Paul, B., Dasgupta, A., \& Bandyopadhyay, L. (2018). Capacity building of private sector workforce for public health services in India: scope and challenges. Indian Journal of Community Medicine. 43(3), 144- 
147.

Sengupta, A., \& Nundi S. (2005). The private health sector in India is burgeoning, but at the cost of public health care. BMJ, 331(7526), 1157-1158.

Shah, U.R., \& Mohanty (2011). Private sector in Indian healthcare delivery: consumer perspective and government policies to promote private sector. Information Management and Business Review, 1(2), 79-87.

Sheikh, K., Saligram, P., \& Hort,. K. (2015). What explains regulatory failure? Analyzing the architecture of healthcare regulation in two Indian states. Health Policy and Planning, 30(1), 39-55.

Shetty, P. (2010). Medical tourism booms in India, but at what costs? Lancet, 376 (9742), 671-2.

Shukla, A., More, A., \& Marathe, S. (2018). Making private health care accountable: mobilizing, civil society and ethical doctors in India. IDS Bulletin. 49(2). Retrieved from https://bulletin.ids.ac.uk/index.php/idsbo/article/view/2970/Online\%20article.

The World Bank (2014a). The World Bank Data. 2014. http://data. worldbank.org/country/india.

Thomas, S.V. (2009). The national health bill 2009 and afterwards. Annals of Indian Academy of Neurology, 12(2), 79.

World Health Organization. (2005). Working with the private sector to achieve public health goals at the country level (draft). The Mantreux challenge-making health systems work. Switzerland. Retrieved from https://www.who.int/management/background_6.pdf.

World Health Organization (2014 b). Global health expenditure database NHA indicators. 2014. Retrieved from http://apps.who.int/nha/database/ViewData/Indicators/en. 